\title{
Processos Formativos na Rede Coque VIVE (RECIFE-PE): CONTRIBUIÇÕES TEÓRICO- METODOLÓGICAS PARA A EDUCOMUNICAÇÃO
}

\author{
Doriele AndRADE-DUVERnOY \\ Universidade de Pernambuco (UPE), Recife, Pernambuco, Brasil
}

\begin{abstract}
Resumo: Este artigo versa sobre os elementos formativos nas atividades desenvolvidas pela Rede Coque Vive (RCV). O trabalho de tese analisou a formação do educomunicador, questionando os contextos de formação e práticas educomunicativas. Buscamos saber de que maneira as interações entre os membros RCV constituem um espaço-meio de formação do educomunicador e como a RCV contribui para a circulação e apropriação de conhecimentos em educomunicação. Adotamos os princípios do estudo de caso etnográfico. Constatamos que as atividades educomunicativas presentes na RCV contribuem para a formação de educomunicadores e para o protagonismo juvenil, indo além da simples apropriação de conteúdos e apontando para outros elementos que fornecem a base para a educomunicação e refletem na formação humana.

Palavras-chave: Rede Coque Vive. Educomunicação. Rede Associacionista. Práticas Formativas.
\end{abstract}

INTRODUÇÃO

O contexto geral desta pesquisa é a educomunicação', tema recorrente no debate atual sobre a relação que estabelecemos com as mídias (individual e coletivamente), o direito humano à comunicação, o empoderamento midiático e o acesso democrático às mídias.

A formação dos educomunicadores e os contextos favoráveis para essa formação constituem nossa problemática central. Adotamos neste trabalho uma compreensão de educomunicador como todos os profissionais 
que desenvolvem atividades educomunicativas, independentemente da sua formação inicial (acadêmica ou técnica). É por isso que nos debruçaremos sobre as práticas educomunicativas e as aquisições oriundas dessas práticas, e não sobre a formação institucionalizada.

A perspectiva teórica utilizada nesse trabalho nos permite defender a ideia de que a educomunicação deve ser entendida como uma urgência na atual conjuntura social. Os desafios da globalização e da"sociedade do conhecimento"destacam a necessidade da educomunicação. É, sobretudo, nos espaços de educação não formal que a educomunicação está se desenvolvendo, pois se a escola é chamada a cumprir a missão de implementar a educomunicação, constata-se que as ações são na sua maioria isoladas e dependentes da sensibilização e do trabalho militante de alguns professores. Nesse contexto, as redes associacionistas apresentam-se como um via alternativa às diversas práticas que não encontram sua efetivação nos sistemas formais de ensino.

É nesse contexto que situamos nosso trabalho de tese, desenvolvida no quadro de Doutoramento da Université Lumière Lyon 2 (França). O estudo das ações da Rede Coque Vive (RCV) nos permite ilustrar as discussões tecidas em torno da formação do educomunicador. ${ }^{2}$ Com dados obtidos a partir de entrevistas, de questionários, de análise documental e de observação, nosso estudo visou a demonstrar os elementos formativos originados em um contexto específico: uma rede associacionista. Não pretendemos, contudo, negar as contribuições das formações institucionalizadas concretizadas pela educação formal. Propomo-nos a mostrar as contribuições dos contextos e princípios que regem a educação não formal para a formação do educomunicador, enfatizando as experiências, que chamaremos de atividades educomunicativas.

Rede Coque Vive: desconstruindo estigmas e construindo novas REPRESENTAÇÕES DA COMUNIDADE DO COQUE

A pesquisa foi conduzida dentro de uma rede associacionista, a Rede Coque Vive (RCV). Esta rede é composta por três atores: Movimento Arrebentando Barreiras invisíveis (Mabi), a Organização Não Governamental - Núcleo Educacional Irmãos Menores de Francisco de Assis (NEIMFA), criada em 1987 e voltada para fins socioeducacionais - e Universidade Federal de Pernambuco (UFPE). No estudo de campo foram identificados 26 membros da RCV diretamente envolvidos nas ações educomunicativas desenvolvidas dentro da rede associacionista. 
Freitas (2005) realizou um estudo sobre o papel das redes associacionistas de educação, no qual o termo associacionismo, visto como a busca de soluções para os problemas por meio da associação de pequenos grupos é tratado de maneira a ultrapassar a teoria meramente econômica, pois ele avança nas discussões acerca do associacionismo cívico, e, assim, nos mostra que atualmente as redes associacionistas são vistas como estratégias de gestão de riscos aos quais são expostos os mais vulneráveis da sociedade. Novos territórios de ação coletiva são criados pelas redes associacionistas e tem o "pertencimento" como a categoria mais importante dessas redes. $\mathrm{O}$ "pertencimento" é então entendido como um sentimento de identidade, produzindo a motivação necessária para a ação coletiva. Assim, ele pode verificar que os membros de uma rede e, suas diferentes formas de participação em associações específicas da sociedade civil, não são unicamente motivados pela afinidade a certos espaços para expressão relacionada às práticas sociais específicas, tais como religião, lazer e esporte, "mas por representarem opções para a consociação, promoção e representação de interesses que não encontram reconhecimento direto no espaço das instituições públicas tradicionais" (FREITAS, 2005, p .43).

Pedro Amador (2010), ao abordar a noção de rede social, entendida como conjunto de relações interpessoais concretas que liga indivíduos, aponta as redes sociais como uma estrutura social dinâmica composta de nós de indivíduos e/ou de organizações. Para ele, essas relações podem se manifestar em diversos níveis e podem ser mantidas por laços de amizade que permitem conservar a esperança e a confiança na rede. Assim, as redes associacionistas constituem campos de sociabilidade estruturados por meio da circulação de bens diversos, representando um terreno favorável para motivar novas formas de ação política e cultural, dado o seu formato horizontal e multicêntrico, o que permite a potencialização de recursos e a criação de novas alternativas na resolução de problemas.

No centro da Rede Coque Vive, situa-se o Coque, comunidade com cerca de 40.000 habitantes, localizada em uma das 66 Zonas Especiais de Interesse Social (ZEIS) da cidade de Recife, criadas a partir da mobilização de Dom Helder Câmara, e pelo Plano de Regularização das Zonas Especiais de Interesse Social (PREZEIS). Cidade atravessada pelos rios Capibaribe e Beberibe, suas pontes, seu mangue e suas desigualdades sociais, marcadas pelo cenário de habitações precárias sobre palafitas, foram denunciadas nas músicas de Chico Science (1966-1997). Dos "mocambos" de Gilbert Freyre (1936) ao "ciclo do caranguejo" de Josué de Castro (1966), um dos elemen- 
tos que nos ajudam a compreender os contrastes da cidade de Recife é a evolução histórica da ocupação do solo. Mas a cristalização de uma imagem negativa da comunidade do Coque é promovida pela especulação política e mobiliária. Essa imagem negativa sobre a comunidade do Coque exerce um forte impacto sobre seus habitantes, devido às violências psicológicas e simbólicas às quais os habitantes dessa comunidade são submetidos cotidianamente por meio de humilhações e violações de seus direitos humanos. João Vale Neto (2007) aponta esses fatores como sendo, por um lado, a gênese da estigmatização e da violência local; e por outro, revela que as ações políticas (privadas ou governamentais) visam principalmente a prevenção da violência em detrimento da promoção dos direitos humanos e da cidadania. Constataram, também que essas ações são geralmente fragmentadas e não reconhecem o potencial de participação dos habitantes para a resolução de seus próprios problemas.

Ampliando o quadro de violações aos direitos, as mídias comerciais locais reforçam uma representação estereotipada dos moradores da comunidade do Coque. Souza Silva (2009) analisou as manchetes de um jornal local impresso entre os anos de 1970 e 2007, e constatou que as mídias, sua linguagem e seu poder, tiveram um papel determinante na manipulação e na consolidação do que é possível, ou não, ser visto sobre a comunidade do Coque. Nesse contexto de degradação social, os moradores perdem a memória de suas construções positivas, de suas mobilizações e de suas resistências, força da estigmatização historicamente promovida pelas mídias.

Nesse contexto, o projeto de extensão universitária: "Coque Vive: comunicação, educação e cultura" originou-se em 2005 na comunidade do Coque, reunindo estudantes de Comunicação Social em Jornalismo da UFPE e jovens que integravam o coletivo MABI. O NEIMFA acolheu o encontro dessas pessoas, contribuindo para que a Rede Coque Vive fosse se tecendo.

Mais do que participar do curso sobre "Leitura crítica das mídias", os jovens do MABI interessavam-se em questionar o papel das mídias locais na produção e veiculação de uma imagem estereotipada sobre os moradores do Coque, sempre os associando ao crime, violência, marginalidade, carência de ajudas diversas. Assim, eles propuseram a produção de um "Jornal do Coque", contando com os conhecimentos em comunicação de estudantes de Jornalismo da UFPE. Somente em 2006, o projeto de extensão universitária "Coque Vive: Comunicação, Educação e Cultura" foi oficializado na Pró-Reitoria de Extensão da Universidade Federal de Pernambuco (PROEXT), institucionalizando as atividades iniciadas na comunidade. Da experiência 
inicial de produção do Jornal do Coque pelos próprios habitantes daquela comunidade em 2005, outros produtos foram idealizados e materializados na comunidade mediante as ações promovidas pela RCV, entre elas pode-se repertoriar, no período de 2006 a 2012: Fanzines "Desclassificados", Revista Mabi, blog Coque Vive, Banco de Imagens Coque Vive, Rádio Coque Livre, Estação Digital de difusão de conteúdos, Vídeo documentários, produções acadêmicas, publicações científicas, biblioteca popular do Coque, livro "Coque Vive Notícias", eventos socioartísticos de divulgação das ações, Cine Coque, Caravana Arco-Íris, circuitos das escolas, seminários acadêmicos, material didático, formação "Agentes de Educomunicação Solidária", essa última com os módulos de análise crítica das mídias, técnicas, imagens, vídeo, fotografia, filosofia, produção textual, cidade e espaço, construção de notícia. Dessas ações, muitas foram contempladas com prêmios de repercussão nacional.

Todas essas ações promovidas pelas RCV tiveram como objetivo principal desconstruir os estigmas e construir novas representações da comunidade do Coque, através da produção de mídias. Mais do que isso, pautados pelo resgate do sentimento de pertencimento, as ações da RCV provocam em seus membros o desejo de resistir aos modelos estabelecidos, instigando novas possibilidades de ser e estar no mundo.

Ao considerarmos o educomunicador como todo sujeito que implementa a educomunicação, seja de maneira teoricamente fundamentada, seja em experimentações, buscamos identificar, na RCV, elementos de formação a partir das interações entre os membros desta rede, para assim verificar se a RCV é um vetor de circulação e apropriação do conhecimento em educomunicação e um espaço de formação do educomunicador.

Antes de detalharmos esses elementos, examinaremos os fundamentos da formação no domínio da Educomunicação.

\section{EDUCOMUNICAÇÃO E FORMAÇÃO DE EDUCOMUNICADORES}

Acreditamos que os educomunicadores são todos os profissionais que implementam projetos educomunicativos, independentemente da sua formação inicial e de seu pertencimento institucional; agregamos também os profissionais que estão envolvidos em experiências educomunicativas, que muitas vezes não são classificadas ou reconhecidas como tal. Mas, em que contexto esses educomunicadores adquirem os conhecimentos específicos necessários para o desenvolvimento de ações educomunicativas? 
Diante disso, precisamos abordar a formação dos educomunicadores. Para isso, nos apoiaremos em diferentes modelos que sustentam a formação de professores, nas diversas maneiras de adquirir competências profissionais e nas questões de formação diante das novas exigências sociais. Isso nos levará a considerar a emergência e atuação do educomunicador na educação formal e não formal. Estaremos diante da aparição de um novo profissional ou de uma redefinição dos papéis dos professores, jornalistas e outros profissionais?

Ao longo do século $X X$, a aproximação entre comunicação, cultura e educação foi enfatizada pelos trabalhos de autores que visavam a uma intersecção entre estes três campos, entre eles: Celestin Freinet (através do jornal escolar), Paulo Freire (através da educação popular), Martin-Barbero (através da sistematização da teoria da mediação), Kaplún (através do desenvolvimento do conceito de comunicador popular), entre outros.

No Brasil, a educomunicação se consolidou ao longo dos anos 19701980, especialmente no meio associativo. Na década de 1990, é possível observar um aumento das rádios comunitárias, baseadas em princípios educomunicativos. A criação da Escola de Comunicação e Educação da Universidade de São Paulo (ECA / USP), em 1991, marcou a produção científica no campo da educomunicação no cenário brasileiro. Dados da Coordenação de Aperfeiçoamento de Pessoal de Nível Superior (CAPES), que catalogam as teses produzidas desde 1987, mostram que a partir de 1998 a educomunicação é evidenciada. Entre 1998 e 2010, foram identificadas 16 teses de Doutorado e 16 dissertações de Mestrado centradas na educomunicação. Deve-se notar que o critério para consultar o banco de dados CAPES foi a palavra exata "educomunicação", somente uma análise mais detalhada dos trabalhos sobre "educação e mídia", "educação e meios de comunicação de massa", "educação e tecnologia", entre outros, nos permitiriam dizer se outros trabalhos se encaixam em uma perspectiva de educomunicação. Assim, é possível apontar a relação entre a criação do Núcleo de Comunicação e Educação da ECA-USP e as primeiras referências científicas sobre o Banco de Teses e Dissertações da CAPES.

Alves (2007) nos mostra que o caminho da educomunicação no Brasil é marcado por duas perspectivas teóricas: a leitura crítica das mídias e a comunicação de resistência. A abordagem da formação crítica diante da mídia é um passo importante na educomunicação, pois a leitura das mídias é colocada no contexto de leitura de mundo, visto que as mídias têm um importante impacto social e são produtos e processos que as crianças e os jovens se apropriam antes mesmo da idade escolar. Mas outras experiências 
mostram que isso não é suficiente para criar um impacto real. É por isso que a comunicação de resistência fornece novas perspectivas sobre a educomunicação. A comunicação de resistência também é conhecida como comunicação popular, alternativa, libertadora, participativa. Mas, parece-nos que o termo "mídia radical" abrange as mídias dos movimentos sociais. As mídias radicais são geralmente em pequena escala e podem assumir várias formas. Elas oferecem uma visão alternativa às mídias hegemônicas.

Para Soares (2002), a educomunicação é compreendida como um "ecossistema comunicacional". A educomunicação é regida pelos princípios de promoção do acesso democrático à produção e à difusão da informação, da recepção crítica sobre o modo como as mídias podem enquadrar nossa percepção do mundo, do uso criativo das mídias, e da expressão comunicativa dos membros de uma comunidade.

A alteridade, a consciência social, o diálogo, a integração social, a cidadania, as relações colaborativas entre sociedade e indivíduos, o processo educativo como espaço público, a aprendizagem como processo coletivo e a democratização das mídias são os ideais buscados pela educomunicação (DOMINGOS DA SILVA, 2009).

Embora no âmbito internacional os termos "Éducation aux médias", "Medias literacy" e "Educação para os meios" sejam considerados equivalentes à educomunicação, epistemologicamente este conceito é expresso no Brasil de forma muito mais ampla, ultrapassando o desenvolvimento de uma "postura crítica face às mídias", e avançando para a criação de ecossistemas comunicativos (ANDRADE-DUVERNOY; REGNIER, 2012).

Nesse sentido, a educomunicação é estreitamente ligada à comunicação popular, que rejeita o processo linear de comunicação (um emissor transmite uma mensagem a um receptor). Mario Kaplún (1985), um dos grandes nomes da comunicação popular, forjou o termo "educomunicador", o que ajudou a consolidar o conceito de educomunicação no Brasil. Inspirado pela ideias de Paulo Freire, Kaplún analisa em sua obra "El Comunicador Popular" a comunicação educativa, ele sistematiza três modelos de educação subjacentes às práticas comunicativas. Assim, ele distingue o modelo centrado nos conteúdos, o modelo centrado nos efeitos e o modelo centrado nos processos.

No modelo centrado nos processos, a troca está no centro das relações e a problematização da realidade física e social é fortemente estimulada. O que importa é aprender a aprender. Nesse modelo, os erros e os conflitos são considerados como uma etapa necessária à criação, e, ao contrário do modelo centrado nos efeitos, a solidariedade e a cooperação são valorizadas. 
Neste sentido, a educação é um processo permanente, que se realiza ao longo da vida através de uma prática reflexiva. O objetivo, neste modelo, é o sujeito que pensa e transforma a sua realidade.

A educomunicação, tal como ela é concebida pela USP, corrobora com as proposições de Porcher (2006), que defende uma "educação à comunicação". Essa concepção uspiana visa à criação de um ecossistema comunicativo em que a comunicação, cultura e educação se cruzam, é regida pelos princípios de acesso democrático à produção e à difusão da informação, de uso criativo das mídias, de expressão comunicativa dos membros de uma comunidade e de gestão comunicativa.

Partindo da ideia de que uma das condições fundamentais para a concretização da educomunicação é a formação de educomunicadores, inferimos que, a formação, as práticas e a profissionalização dos educomunicadores constituem um dos principais eixos de sustentação de projetos educomunicativos.

Não desconsiderando as formações institucionalizadas do educomunicador, a nossa problemática centra-se na diversidade de contextos favoráveis para essa formação. Para isso, adotamos neste trabalho uma compreensão de educomunicador como todos os profissionais que desenvolvem atividades educomunicativas, independentemente da sua formação inicial. É por isso que vamos nos concentrar nas práticas educomunicativas e nas aquisições oriundas dessas práticas. Vejamos alguns pontos a considerar sobre formação.

Do ponto de vista das finalidades da aprendizagem, Develay (1994) identifica cinco tipos de formação: o "ter" (a formação como informação), o "fazer" (formação como ativação), o "ser" (formação como desenvolvimento), o "comunicar" (formação como comunicação) e o "mudar" (formação como transformação).

Develay (1994) indica que é possível distinguir três tipos de formação, todos voltados para a função social da formação, o que ele chama de "tipos de trabalho pedagógico". Estes três tipos de formação são: o tipo transmissivo, de orientação normativa que reduz o indivíduo a objeto da formação; o tipo incitativo, de orientação pessoal, em que o indivíduo é o sujeito de sua formação; e finalmente, o tipo apropriativo, focado na inclusão social, em que o indivíduo é o agente de sua formação.

Nosso interesse é sobre o modelo apropriativo, já que ele oferece pistas para o trabalho de formação praticado na RCV. Neste modelo, centrado na inclusão social, o conhecimento é visto como uma necessidade e a pedagogia é voltada para quebrar as determinações sociais. $O$ trabalho é 
feito em comum, pela apropriação do real e pela definição dos referenciais. No modelo apropriativo, a dialética fundamenta o ato de formação pelo reconhecimento da realidade pedagógica, social, cultural e profissional das pessoas em formação.

Considerando a concepção do sistema social como fator determinante sobre a concepção de formação, Maggi (2000) parte da ideia que toda formação é ativada pelo seu contexto. Para ele, é a maneira como concebemos o contexto que irá determinar os modos de formação concretizados. Nesse ponto, a identificação dos agentes de promoção de estigmas sobre a comunidade do Coque, como um ponto de partida das ações, permitiu que os habitantes dessa comunidade refletissem sobre o seu lugar de pertencimento e buscassem as chaves de mudança.

No que diz respeito às maneiras de adquirir as competências profissionais, nos apoiamos em Nadot (2000). Ela identificou dois grandes grupos de situações de formação: o conhecimento dos outros (transmitido ou discutido) e as práticas profissionais (discutidas ou efetivas). As situações de aprendizagem teóricas são categorizadas por esta autora como: "aprender ouvindo" (caracterizada pelo discurso do outro sobre uma ação); aprender observando (o conhecimento não é enunciado, ele é a ação; a observação de uma prática para construir uma melhor representação do conhecimento envolvido na ação); aprender dizendo (trocas e reflexões sobre a prática profissional; análise das práticas docentes, o discurso sobre a ação, visando a inteligibilidade da ação); aprender fazendo (o sujeito constrói sua prática praticando, a construção do conhecimento é através da ação. A ação é a fonte e o local de reflexão).

Nadot (2000) conclui com essa categorização que a ação oferece uma ampla gama de conhecimentos (aprender observando, aprender fazendo). Ela também afirma que a formação do que foi experimentado e a discussão das decisões tomadas "intuitivamente" permite ao sujeito identificar o conhecimento e o trabalho que direcionou sua ação (aprender a dizer). A prática (aprender fazendo) é um complemento essencial para os outros métodos de aquisição de profissionalização. Essa relação entre o que se sabe o que se vê no ambiente onde se deve agir é um importante instrumento de construção da prática profissional.

Ao falarmos de formação profissional em educação, somos levados a tratar da formação de professores para atuarem em espaços formais e não formais de educação. No entanto, a formação de professores é muitas vezes criticada pela análise das práticas de ensino e por seu impacto na aprendiza- 
gem dos alunos. Esse fato nos leva a refletir sobre os saberes proporcionados pela formação institucionalizada e a garantia da ação docente esperada. Neste sentido, Silva (2010) aponta que não temos garantia de que, no final de um processo de formação, este profissional vai se envolver em um projeto existencial para educar e formar outros sujeitos pela sua humanização. Para ele, a certificação através de diploma profissional não é uma garantia.

Nadot (2000) diz que não pode pretender à formação oferecer"produtos acabados". Pelo contrário, a formação inicial de professores deve ser entendida como a primeira fase de um longo processo de desenvolvimento profissional. Existem diferentes formas de apropriação do conhecimento, do saber-fazer, para o desenvolvimento de um saber-ser, o que constitui uma totalidade.

Podemos considerar que quando os futuros professores começam sua formação, eles já têm aquilo que Develay (1994) chamou de "modelo de aprendizagem implícita", entendido como uma síntese de suas próprias metas para seu trabalho docente, certa concepção da criança, uma imagem dos saberes a ensinar e uma idealização do papel que parece necessário assumir, incluindo uma certa visão de ensino-aprendizagem.

Esse modelo é uma construção abstrata que atravessa a prática real e está presente na mente do futuro professor, mesmo que de maneira não expressa. As categorias de atividades presentes no processo de formação (instrução, pesquisa, observação, experimentação, reflexão, treino, estágio de regências etc.) podem contribuir para a construção do modelo pedagógico personalizado dos futuros professores. No final da formação, cada professor constrói o seu próprio estilo de ensino, que é um resultado do processo de formação que liga o"modelo pedagógico implícito" dos futuros professores e o "modelo pedagógico de referência" do formador. Este modelo pedagógico personalizado é regido pelo processo de rejeição, de mistura ou de adesão total.

Tratando-se da formação do educomunicador, que tipo de formação pensar?

Domaille e Buckigham (2001) em um relatório apresentado à UNESCO sobre a educomunicação no mundo constataram que a formação de professores apresenta um caráter diversificado de um país para outro: da formação inicial para algumas especialidades de ensino à formação continuada numa perspectiva de promoção interna nos estabelecimentos escolares, como também, da formação curta e voluntária às associações parceiras que oferecem formação aos professores sensibilizados.

Em 2007, ou seja, 25 anos após a adoção da Declaração de Grünwald, reuniram-se em Paris, representantes políticos, especialistas, professores e 
profissionais das mídias com dois objetivos: fazer um balanço dos avanços e obstáculos encontrados na implementação dos dispositivos e práticas de educomunicação; e fazer recomendações destinadas a difundir a educação para as mídias ${ }^{3}$ e mobilizar todos os interessados. Assim, foram traçadas 12 recomendações, chamadas "Agenda de Paris", organizadas em quatro troncos: 1) O desenvolvimento de programas integrados em todos os níveis de ensino; 2) Formação de educadores e sensibilização dos diversos atores na esfera social: 3) Pesquisa e redes de divulgação; 4) Cooperação internacional traduzida em ações. Além disso, o documento especifica a necessidade de se levar em conta alguns fatores determinantes: os fundamentos políticos, o currículo, a formação de professores e outros mediadores, o papel das indústrias das mídias, a participação dos pais, os recursos didáticos, a pesquisa e avaliação e, finalmente, o intercâmbio e o diálogo em escala internacional.

Essas indicações partem do pressuposto que a educomunicação deve garantir às pessoas: a análise crítica e a criação de suas próprias mídias; a interpretação das mensagens e os valores veiculados pelas mídias; a demanda de acesso às mídias para a recepção e produção; como também, a escolha de mídias para que os jovens possam comunicar suas próprias mensagens, suas histórias e alcançar o seu público alvo.

A educomunicação algumas vezes é reduzida a um "aprender sobre as mídias", que inclui uma análise crítica e uma produção criativa. Dessa forma ela pode e deve ter lugar na educação formal e não formal a fim de promover o senso crítico, a responsabilidade social, bem como a realização pessoal. No entanto, esse "aprender sobre as mídias" deve estar respaldado num projeto social mais amplo para que não se reduza as práticas aos aspectos meramente técnicos.

Uma maneira de pensar sobre a formação do educomunicador é considerar as competências que as pessoas devem desenvolver em suas relações com as mídias. David Buckingham (2001) aponta alguns conteúdos. Em princípio, a capacidade de fazer a ligação entre os fundamentos das diferentes mídias. Para este autor, o currículo da educomunicação deve abordar os seguintes temas: a) as mídias como organismo (quem comunica o quê e por quê?); b) as mídias e suas categorias (tipos de textos, formas, gêneros); c) as mídias e suas tecnologias (como esse texto foi produzido); d) as mídias e suas linguagens (o que significa, o sentido, códigos, estruturas narrativas); e) as mídias e seus públicos (quem é o receptor? o que ele retém? como responde?); f) as mídias e as representações (como o texto apresenta o tema? os estereótipos e consequências). 
No entanto, a delimitação desses temas-chave suscita questionamentos por sua simplificação, sobre os valores, as atitudes e competências que as pessoas devem adquirir e finalmente sobre a avaliação da mudança. Para Catherine Becchetti-Bizot e Alain Brunet (inspetores do Ministério da Educação Francesa, que escreveram um relatório sobre as questões, o estado e as perspectivas da educação para as mídias na França), os conhecimentos básicos nesta área devem ser orientados em três áreas de especialização: a estética, a semiótica e a cívica.

Esses elementos podem abrir novas perspectivas políticas e educacionais, pois a formação dos educomunicadores não pode ser apenas uma atividade isolada, restrita à formação inicial ou ao compromisso dos professores e jornalistas. As políticas públicas são necessárias para incentivar a formação e implementação da educomunicação de maneira efetiva. As mídias não são neutras, elas produzem e transmitem uma visão de mundo e de homem. Longe de se contrapor às mídias, os educomunicadores devem reconhecer as demandas de seu tempo e as potencialidades desses recursos, com rigor metodológico no uso e no estudo das mídias, visando a uma desconstrução e revisão de suas especificidades. A ação não deve estar centrada unicamente no uso das mídias, mas discutir "as mídias estão a serviço de quem?". Essa questão mostra que as mídias não são boas ou más em si, mas são os usos que as determinam. Identificamos o que fundamenta estas práticas, a fim de compreender a sua razão de ser.

Em 2010, o Ministério da Educação, através da Secretaria de Educação a distância (SEED), formalizou parcerias com Secretarias de Educação e 32 Universidades do Brasil, disponibilizando na plataforma E-Prolnfo um curso intitulado "Mídias na Educação" para professores da Educação Básica. Estruturado em módulos, o curso oferece três níveis de certificação: Básico (120 horas), Intermediário (180 horas) e Avançado (360 horas). O curso destina-se a formar professores na análise crítica da mídia e produção de projetos educacionais com as mídias. Um dos módulos do curso aborda a educomunicação, visando a identificar e problematizar o ecossistema comunicativo da escola, por meio da promoção do diálogo e da expressão dos agentes envolvidos.

Vale salientar o pioneirismo da Universidade Federal de Campina Grande (UFCG) que em 2009 criou o curso de Comunicação Social, com habilitação em Educomunicação, sendo o primeiro Bacharelado na área de Educomunicação. Em 2011, uma Licenciatura em Educomunicação passou a ser oferecida pela ECA/USP. Encontramos também cursos de pós-graduação lato sensu em Educomunicação na ECA/USP; no Centro Universitário de Curitiba; na 
Faculdade de Educação e Cultura Montessori (São Paulo). Os cursos oferecidos têm como objetivo formar profissionais preparados para ser um gestor de comunicação no espaço educacional. Um profissional que conhece a teoria e prática da comunicação e da educação com o propósito promover atividades interdisciplinares, seja no ensino ou na coordenação dessas ações. Os espaços formais, não formais e informais de educação são considerados possíveis áreas para a ação deste profissional. Ele também pode exercer a função de consultor em educomunicação para as empresas, organizações, associações, escolas e mídias, implementando projetos educomunicativos nas instituições.

Se por um lado, a formação em educomunicação se destina a criar um novo profissional, por outro lado, é necessário considerar todos os profissionais que há muito tempo realizam atividades educomunicativas nas mais diversas áreas sem necessariamente ter uma certificação para isso.

Tomemos por exemplo a tese desenvolvida por Silva (2010) sobre a constituição da identidade do arte-educador e o papel formativo das experiências de vida na construção e consolidação dessas identidades. Ele mostra que, no campo da arte-educação, alguns arte-educadores acumularam conhecimentos de experiências através de seus percursos profissionais, mas têm dificuldade em serem reconhecidos por seus pares por causa da ausência de certificação específica em Educação Artística. Assim, ele aponta os conflitos internos entre os "arte-educadores não certificados" e os "arte-educadores certificados", indicando que esses conflitos podem levar a uma depreciação no campo da arte-educação, já que esta área ainda está à procura de um verdadeiro reconhecimento no domínio da Educação e da Arte.

Embora no campo da educomunicação ainda não tenhamos encontrado trabalhos indicando este tipo de conflito, é preciso reconhecer o impacto das políticas públicas de formação acadêmica na legitimação dos profissionais que têm práticas educomunicativas consolidadas em vários setores da sociedade e um possível início de tensões.

O educomunicador na Rede Coque Vive: diálogos, Vínculos e pertencimento PROMOVENDO SABERES EM EDUCOMUNICAÇÃO

Da ideia de um sujeito que se apropria de conteúdos da educomunicação, lançamos um olhar sobre as interações, a fim de captar não só o conteúdo, mas também os recursos relacionados à formação desses sujeitos, em um sentido mais amplo. 
O trabalho de campo nos permitiu realizar um mapeamento das interações (entre educomunicadores, entre educomunicadores e jovens da comunidade do Coque, e entre educomunicadores e jovens e instituições ou associações), e também conhecer suas concepções sobre educomunicação, Pedagogia e abordagens pedagógicas que permeiam suas ações educomunicativas dentro da RCV. Por meio da análise documental e observação participante pudemos conhecer algumas estratégias para implementação da educomunicação. A partir desses elementos, pudemos compreender como os membros da RCV passaram a conceber o "comunicar" e o "educar" nesta nova perspectiva educomunicativa. O rico acervo de atividades concluídas e as entrevistas realizadas nos ofereceram elementos de compreensão das relações estabelecidas entre os educomunicadores, os jovens e a pedagogia.

Mais do que os conteúdos específicos da educomunicação, nos defrontamos com suas concepções de formação humana, formação profissional e aquisição de conhecimento que, em seu conjunto, nos indicam o diálogo e o vínculo como parte primordial da formação integral. O diálogo promovido pelas ações da RCV possibilitou dar um novo sentido à existência desses jovens do Coque e à sua comunidade. $O$ verdadeiro diálogo, visando à compreensão do outro, a desfragmentação das relações humanas, e potencializando a sensibilidade nas relações. Esse tipo de diálogo une o que os preconceitos separam.

Evocando essas interações como situações de aprendizagem, destacamos as condições e circunstâncias que podem levar o educomunicador a construir novos conhecimentos e desenvolver competências em educomunicação. Assim, privilegiamos a perspectiva de sujeitos que, através das interações, se apropriam de recursos variados. Encontramos vários elementos que indicam as contribuições da RCV para a formação do educomunicador. Mais precisamente, as suas ações provocaram nos membros da rede um constante questionamento sobre o significado profundo de educação e de comunicação. Eles experimentaram a aprendizagem de novas formas de ver e praticar a comunicação, por exemplo, o contato humano como uma prática participativa de relacionamento com os outros.

O trabalho desenvolvido pela RCV é também focado nas respostas que os indivíduos dão aos conteúdos e aos estereótipos que as mídias veiculam, em outras palavras, o que as pessoas fazem dos conteúdos e representações que as mídias hegemônicas propõem.

Este processo se realiza através da reflexão sobre a prática, promovendo a construção de conhecimentos exigidos pelo contexto, no qual o 
estabelecimento de laços é a condição sine qua non para a realização da "educomunicação". Esses elementos de formação podem constituir uma contribuição significativa para as formações institucionalizadas de professores, jornalistas e, mais precisamente, de educomunicadores.

Vimos então que esses conhecimentos não são apenas relacionados aos conteúdos, mas às estratégias, à gestão do espaço comunicativo, ao desenvolvimento da expressão pessoal. Os membros da RCV estão envolvidos em um processo de formação que vai além da apropriação de conteúdos e do olhar crítico em relação às mídias, buscando promover o "estar junto", como base para formação humana e como condição essencial para a aquisição de conhecimentos em educomunicação.

É a partir disso que eles promoveram a educomunicação comunitária, construindo e ampliando percepções, imagens, discursos, a fim de intervir e limitar o desenvolvimento de estigmas negativos sobre a comunidade do Coque e seus habitantes. O que corrobora com as proposições de Porcher (2006) que defende uma "educação à comunicação".

$\mathrm{Na} \mathrm{RCV}$, as ações e as aprendizagens se produzem simultaneamente na concretização das ações, colocando em valor o processo, mais que os resultados. Assim, a aprendizagem não é vista somente como uma simples aquisição de saberes, mas como um processo de participação social. Dessa forma, as experiências que analisamos no seio da RCV nos permitem afirmar que esta rede constitui um espaço formativo para os educomunicadores. Esta rede, através de suas atividades, promoveu formas diversificadas de ação e novas experiências de formação e transformação.

\section{Conclusão}

Evidenciando as práticas educomunicativas na RCV, buscamos apontar as suas contribuições na formação dos educomunicadores. O estudo dessa rede associacionista nos permitiu identificar vários elementos intrínsecos à educomunicação. A Rede Coque Vive criou um ecossistema comunicativo na medida em que ampliaram os espaços de comunicação de uma comunidade, até então marcada pela ausência de voz nas mídias. A RCV constitui um espaço legítimo de práticas educomunicativas que privilegiam o diálogo, o senso de pertencimento, o comprometimento, a criação e fortalecimento de laços de afeto. Esta rede, através de suas ações, estabeleceu uma comunicação que vai além dos produtos midiáticos, promovendo uma linguagem em comum 
entre a educação e a comunicação, numa busca constante de novas formas de ação e de novas experiências de formação e transformação.

Acreditamos que as ações que se apoiam nos ideais da educomunicação podem contribuir na formação de profissionais comprometidos com a justiça social e os direitos humanos. Nesse processo de desenvolvimento do protagonismo juvenil, ampliam-se as possibilidades de formação humana e profissional.

Constatamos que nas atividades educomunicativas na RCV, as interações entre os membros envolvidos são um componente-chave para a aquisição, produção e compartilhamento de conhecimentos. Esses conhecimentos não são apenas relacionados à apropriação de conteúdos, mas às estratégias, à gestão do espaço comunicativo, à promoção da expressão pessoal.

A noção de educomunicação propiciou uma análise, ao mesmo tempo, tensa e complexa das relações entre comunicação e educação com implicações significativas para os problemas relativos à formação humana na contemporaneidade em um contexto atravessado por múltiplos discursos de crise em torno da educação e da escola.

As ações desenvolvidas pela Rede Coque Vive devem ser associadas a um movimento acadêmico de educomunicação no Brasil. Além das contribuições que este trabalho pode oferecer no campo da educação e comunicação, buscamos contribuir para a legitimidade dessas práticas educomunicativas e para as reflexões sobre educomunicação.

Por fim, esperamos que essas ações educomunicativas promovidas pela Rede Coque Vive possam oferecer elementos necessários à reflexão sobre as políticas públicas de formação de educomunicadores, indo além de ações focadas em aspectos técnicos, buscando a promoção de uma autêntica participação social.

FORMATIVE PROCESSES IN THE COQUE VIVE NETWORK (RECIFE-PE): THEORETICAL AND METHODOLOGICAL CONTRIBUTIONS TO EDUCOMUNICATION

ABSTRACT: This article addresses the formative elements identified in the activities developed by the Coque Vive Network (RCV, from the original in Brazilian-Portuguese). The thesis work examined the training of the educomunicator, questioning the 
educomunication training contexts and practices. We seek to know how the interactions between the RCV members constitute a space/means for the training of the educomunicator and how the RCV presents itself as a movement of dissemination and appropriation of knowledge in educomunication. We adopt the ethnographic case study approach. We note that the educomunication activities present in the RCV contribute to the formation of educommunicators and to youth participation. This knowledge is not only related to the appropriation of content, but to other elements that provide the basis for knowledge about educomunication and reflect the development of the individual as a human being.

KEYwords: Coque Vive Network. Educomunication. Associationistic network. Formative practices.

\section{PROCESOS FORMATIVOS EN LA RED COQUE VIVE (RECIFE-PE): CONTRIBUCIONES TEÓRICO-METODOLÓGICAS PARA LA EDUCOMUNICACIÓN}

RESUMEN: Este artigo versa sobre los elementos formativos identificados en las actividades desarrolladas por la Red Coque Vive (RCV). El trabajo de tesis desarrollado analizó la formación del educomunicador, cuestionando los contextos de formación y prácticas educomunicativas. Buscamos saber de qué manera las interacciones entre los miembros RCV constituyen un espacio-medio de formación para el educomunicador y cómo la RCV contribuye para la circulación y apropiación de conocimientos en educomunicación. Adoptamos los principios del estudio de caso etnográfico. Constatamos que las actividades educomunicativas presentes en la RCV contribuyen para la formación de educomunicadores y para el protagonismo juvenil, ultrapasando la simplicidad de apropiación de contenidos y direccionado hacia otros elementos que fornecen la base para la educomunicación y se manifiestan en la formación humana.

Palabras-clave: Red Coque Vive. Educomunicación. Red Asociacionista. Prácticas Formativas.

\section{NOTAS}

1) Quanto ao neologismo recente educomunicação, já podemos usar em inglês educomunication, visto que o termo tem sido usado em textos divulgados pela Unicamp, USP e em algumas revistas indexadas.

2) A partir desta pesquisa, produzimos em 2012 um artigo científico, em coautoria com Jean Claude Régnier, enfatizando as contribuições da Rede Coque Vive para a Extensão Universitária. Uma parte das discussões sobre a educomunicação foi aqui reutilizada, 
visto que estas discussões nos permitiram dar ênfase a outros domínios impactados pelas ações da Rede Coque Vive. (Cf. ANDRADE-DUVERNOY, D.; RÉGNIER, J.C., 2012)

3) Em português do Portugal: educação para os media. Em francês: éducation aux médias. Em inglês: Média Literacy/ educommunication (recentemente incorporado).

\section{REFERÊNCIAS}

ALVES, P. H. Educom.rádio- uma política pública em educomunicação. 2007. 142 f. Tese (Doutorado em Ciência da Comunicação) - Escola de Comunicação e Artes. Universidade de São Paulo, 2007.

AMADOR, P. A. Q. As formas de governo da juventude na contemporaneidade: um estudo sobre a "Rede Coque Vive". 2010. 145 f. Dissertação (Mestrado em Educação) Centro de Educação. Universidade Federal de Pernambuco. Recife, 2010.

ANDRADE-DUVERNOY, D.; RÉGNIER, JEAN-CLAUDE. A educomunicação como princípio indissociável da extensão universitária, do protagonismo juvenil e da coesão social: o caso da rede coque vive. Poiésis-Revista do Programa de Pós-Graduação em Educação, v. 5, p. 149-164, 2012.

DEVELAY, M. Peut-on former les enseignants ? Paris: ESF éditeur, 1994.

DOMAILLE, K.; BUCKINGHAM, D. Enquête sur l'éducation des jeunes aux médias. Rapport Final, nov. 2001, Secteur de la communication et de l'information de l'UNESCO. Université de Londres, 2001.

DOMINGOS DA SILVA, F. P. Princípios Educomunicativos: Uma análise sobre a Série Infantil Cocoricó da TV Cultura de São Paulo. Intercom - Sociedade Brasileira de Estudos Interdisciplinares da Comunicação, Congresso de Ciências da Comunicação na Região Sudeste, 14, 2009, Rio de Janeiro. Anais... Rio de Janeiro, 2009. p. 94-115.

FERREIRA SILVA, I. F. C. Discursos sobre espaços populares na Web: investigação de estigmas sobre a comunidade do Coque. 116f. 2011. Dissertação (Mestrado em Comunicação) - Centro de Artes e Comunicação, Universidade Federal de Pernambuco, Recife, 2011.

FREITAS, A. S. Fundamentos para uma sociologia crítica da formação humana: Um estudo sobre o papel das redes associacionista. 2005. $166 \mathrm{f}$. Tese (Doutorado em Sociologia) CFCH. Universidade Federal de Pernambuco, Recife, 2005.

KAPLUN, M. El comunicador popular. Quito: édition Ciespal, 1985. 264 p.

MAGGI, B. Les conceptions de la formation et de l'éducation. In: MAGGI, B. (dir) Manières de penser, manières d'agir en éducation et en formation. Paris: PUF, 2000.

NADOT, S. Des savoirs à la pratique. In : Blanchard-Laville, C. et Nadot, S. Malaise dans la formation des enseignants. Paris : I'Harmattan, 2000. 
PORCHER, L. Les médias entre éducation et communication. Paris: Vuibert/Clemi, 2006. 210 p.

SILVA, E. M. A. A formação do arte/educador: um estudo sobre história de vida, experiência e identidade. 2010. 285 p. Tese (Doutorado em Educação). Centro de Educação. Universidade Federal de Pernambuco. Recife, 2010.

SOARES, I. O. Gestão comunicativa e educação: caminhos da educomunicação. Comunicação \& Educação. São Paulo, v. 23. jan./abr. p. 16-25, 2002

SOUZA SILVA, R. F. O Coque encontrado no jornal diário: análise dos temas do discurso jornalístico sobre o bairro do Coque observados no Diário de Pernambuco entre 1970 e 2007. Trabalho de conclusão de Curso (Bacharelado em Comunicação Social). Centro de Artes e Comunicação. Universidade Federal de Pernambuco, Recife, 2009.

VALE NETO, J. Coque, Morada do Vínculo. Relato de uma pedagogia da communicação a partir da extensão universitária. Trabalho de conclusão de curso. (Bacharelado em Comunicação Social). Centro de Artes e Comunicação. Universidade Federal de Pernambuco. Recife, 2007.

Doriele Andrade-Duvernoy: Graduada em Pedagogia pela Universidade Federal de Pernambuco (UFPE), mestre e doutora em Educação pela Université Lumière Lyon 2 (Lyon II). Professora Adjunta Universidade de Pernambuco (UPE).

E-mail: doriele.andrade@smail.com 
